\title{
A comprovação da relação volume $x$ variância na homogeneização da sílica em minério de ferro
}

\author{
(The evidence of the volume $x$ variance relationship in the \\ homogenization of silica in iron ore)
}

\section{Diego Machado Marques \\ Engenheiro de Minas Mestrando, PPGEM-UFRGS \\ E-mail:diegommarques@yahoo.com.br \\ João Felipe Coimbra Leite Costa \\ Engenheiro de Minas Prof. Dr., DEMIN, UFRGS \\ E-mail: jfelipe@ufrgs.br}

\section{Diniz Tamantini Ribeiro}

Geólogo, DSc, Vale E-mail:diniz.ribeiro@vale.com

\section{Roger Luis Stangler \\ Geólogo, MSc Doutorando, PPGEM-UFRGS Anglo Ferrous Brazil \\ E-mail: \\ roger.stangler@angloferrous.com.br}

\section{Emir Birro de Castro}

Eng. de Minas, MSc Ferrous Resources Brasil E-mail:emir.birro@ferrous.com.br

\section{Jair Carlos Koppe}

Engenheiro de Minas, Geólogo Prof. Dr., DEMIN, UFRGS E-mail: jkoppe@ufrgs.br

\section{Resumo}

Combinações de minério provenientes de diferentes frentes de lavra e pilhas de homogeneização são, comumente, empregadas para reduzir a variabilidade dos teores nas plantas de beneficiamento. A metodologia proposta, nesse trabalho, visa a quantificar a variabilidade das diversas etapas em um sistema de homogeneização. O parâmetro químico avaliado é sílica $\left(\mathrm{SiO}_{2}\right)$ de minério de ferro, na faixa granulométrica inferior a 0,15 mm. Este é um contaminante errático, nesse tipo de depósito. Os resultados mostram a variância esperada para os diversos tamanhos de pilhas. Fica demonstrado que a variância, reduz com o aumento da massa da pilha.

Palavras-chave: Pilha, homogeneização, redução de variabilidade, minério de ferro.

\section{Abstract}

Blending and homogenization piles are usually employed for reducing head grade fluctuation at a processing plant. The methodology suggested herein aims at quantifying the variability at various stages in a homogenization system. The chemical parameter evaluated is silica $\left(\mathrm{SiO}_{2}\right)$ from an iron ore at a granulometry below $0.15 \mathrm{~mm}$. This is a highly variable contaminant in iron ore deposits. The results show the expected variance among the grades for various pile sizes. It is demonstrated that the rate of variance decreases as the pile size increases.

Keywords: Piles, homogenization, variability reduction, iron ore.

\section{Introdução}

O minério proveniente da lavra pode apresentar variações, nas suas características, devido às heterogeneidades dos materiais que o compõem. Essas heterogeneidades podem ser avaliadas em inúmeros níveis de escala e tamanho. Os tipos de heterogeneidades encontrados, durante a preparação e processo, estão relacionados, essencialmente, com o processo de formação do depósito mineral, com os métodos de carregamento e transporte e os tipos de procedimentos empregados, na manipulação e preparação do minério. Segundo Schofield (1980), as etapas de carregamento, transporte, britagem, moagem, armazenamento e manipulação 
contribuem, de alguma forma, na variabilidade do material, já que introduzem certa quantidade de re-estruturação da distribuição espacial da mineralização natural. Sendo assim, espera-se que o aumento, no suporte amostral, traga redução na variabilidade dos minérios analisados (Parker, 1979).

Para se estabelecer a qualidade de um minério, é necessário, primeiramente, realizar uma amostragem, onde a variabilidade observada, para um resultado em particular, deve ser associada ao tamanho da amostra utilizado. A amostragem de um depósito mineral origina-se da possibilidade teórica de dividir um todo em pequenas porções, que serão, separadamente, analisadas. Esse conceito permite uma descrição qualitativa e quantitativa da variabilidade para um determinado tamanho de amostra tendo-se como base a teoria da amostragem (Gy, 1998).

Realizando esse procedimento de amostragem, nas diversas etapas que compõem as atividades mineiras, podese identificar e quantificar as variabilidades presentes em cada uma delas. Essas variabilidades devem ser controladas quando se pretende fornecer à usina de beneficiamento um produto de qualidade aceitável e reduzir os custos com o tratamento dos minérios. Isto se torna possível através da análise estatística dos dados, identificando o impacto que cada etapa apresenta sobre a variabilidade do sistema.

Nesse trabalho, serão analisadas as variabilidades presentes nas etapas de transporte e homogeneização do minério de ferro, analisando o ganho para a usina de beneficiamento com uso de pilhas de homogeneização, em comparação com o material proveniente diretamente da mina e com a blendagem realizada com diferentes minas.

\section{Metodologia}

Antes de iniciar a análise da redução de variabilidade com o aumento do volume na produção de minério de ferro, faz-se necessário o entendimento de todos os possíveis parâmetros que influenciam esse sistema. As principais fontes de variabilidade podem ser assim listadas:

- Variabilidade intrínseca dos teores na Mina 1.

- Variabilidade intrínseca dos teores na Mina 2.

- Variabilidade dos teores no material de alimentação da pilha de homogeneização (pré-pilha combinando minério de várias frentes de lavra e de duas minas).

- Variabilidade dos teores das pilhas de homogeneização em função de diferentes massas que as compõem (variabilidade entre-pilhas).

A Figura 1 mostra uma representação esquemática do sistema analisado. Os pontos em destaque representam as amostragens realizadas nesse sistema, onde as variabilidades são apresentadas em forma de gráficos (os quais serão detalhados mais adiante). Os resultados de variabilidade obtidos são apresentados através do coeficiente de variação $\left(\mathrm{CV}=\sigma / m_{\mathrm{a}}\right)$.

Com o banco de dados com informações de produção, foi possível resgatar os dados históricos de cada uma das etapas que compõe o sistema de homogeneização no ano de 2004. A menor escala de tempo disponível, contendo os dados qualitativos e quantitativos, corresponde ao turno de trabalho da empresa. A variável analisada é a sílica $\left(\mathrm{SiO}_{2}\right)$, na faixa granulométrica inferior a $0,15 \mathrm{~mm}$, bastante errática nesse tipo de depósito mineral.

Os dados foram ordenados em relação à sua massa, de forma crescente, e, posteriormente, agrupados a cada cinco turnos, iniciando na menor massa e seguindo a divisão dos grupos de forma linear.

Sabe-se que os teores de cada turno serão diferentes entre si e diferentes da média global calculada do ano. Entretanto, quando ocorre o agrupamento da massa em lotes maiores, o teor médio do lote aproxima-se do teor médio anual, em comparação aos teores calculados com amostras extraídas da massa dos turnos. Esse princípio de redução da variância de dispersão com o aumento do suporte (Figura 2) é bem conhecido pelos geoestatísticos.

De posse desses resultados, foi possível fazer uma análise comparativa entre as variabilidades das minas analisadas e mostrar o impacto da blendagem com diferentes frentes de lavras (minas), aqui chamada de pré-pilha, na qualidade do produto final.

\section{Resultados e discussão}

\section{Variabilidade pré-produto}

Denominamos, aqui, de pré-produto o material proveniente das Minas 1 e 2. Apesar de os lotes analisados não apresentarem o mesmo suporte amostral, não há uma variação significativa de massa nessa etapa.

\section{Mina 1}

Os lotes de massa analisados a cada turno na mina 1 têm uma média de 8.600 toneladas e um desvio-padrão de, aproximadamente, 2.000 toneladas (Figura 3a). O desvio-padrão dos teores de sílica dos grupos de 5 turnos, em relação ao teor médio anual do minério, nessa mina, é de $2,63 \%$.

\section{Mina 2}

Os lotes analisados, em cada turno, nessa mina, têm uma massa média ligeiramente inferior aos da Mina 1, sendo de, aproximadamente, 8.200 toneladas, porém apresentam um desvio-padrão bem superior, sendo esse referido esvio de, aproximadamente, 3.000 toneladas (Figura 4a). O desvio-padrão dos teores de sílica dos grupos de 5 turnos, em relação ao teor médio anual, nessa mina, é de $2,78 \%$.

Pode-se perceber, a partir dos resultados das Figuras 3 e 4, que a planta de beneficiamento alimentada diretamente com o material proveniente dessas minas apresentaria dificuldades em ser operada, dada a variabilidade dos teores de alimentação. 


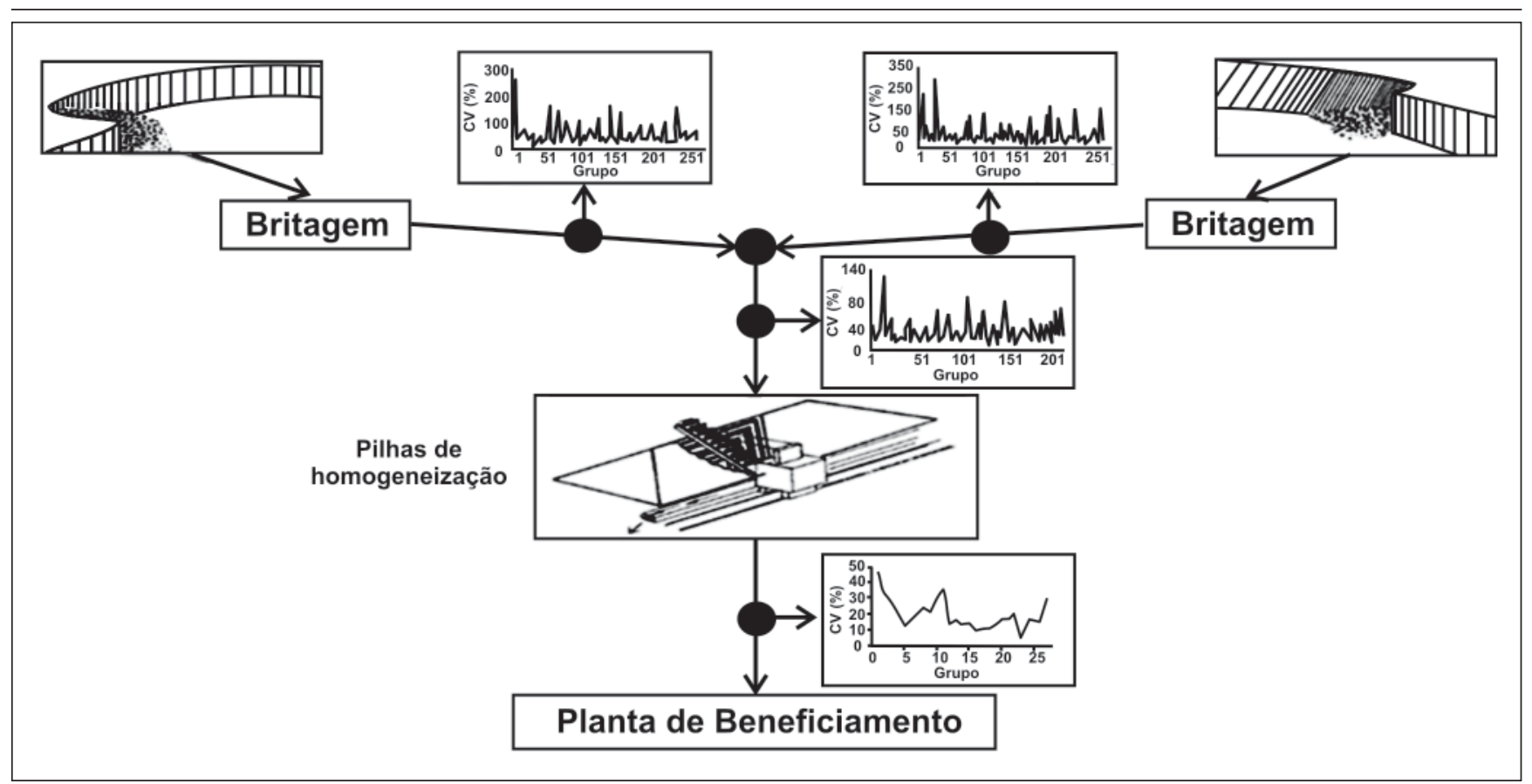

Figura 1 - Esquema de redução da variabilidade no sistema.

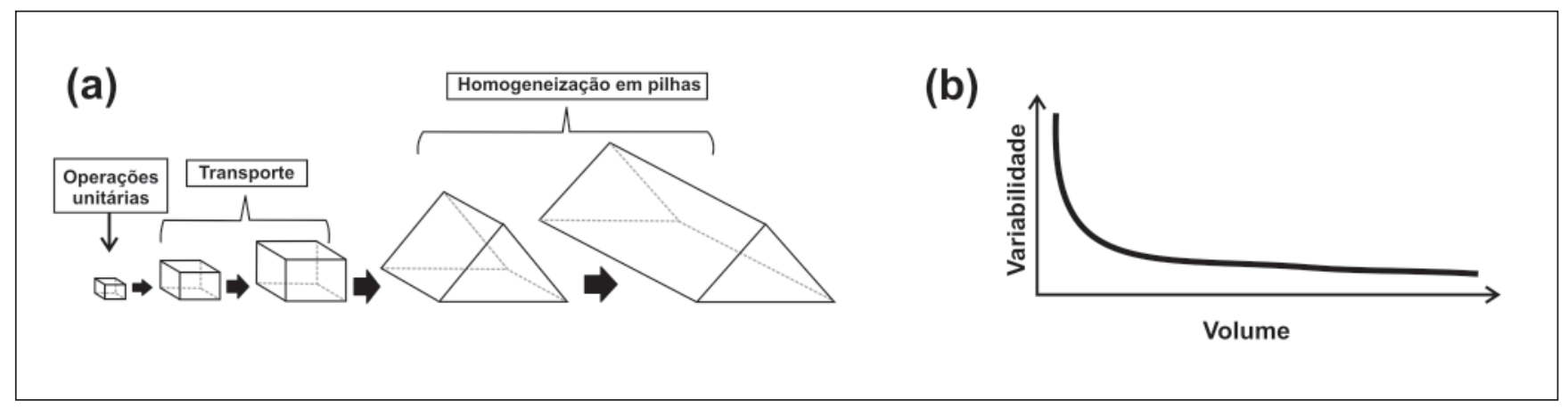

Figura 2 - Comportamento da variabilidade dos teores entre lotes com o aumento do suporte (massa ou volume) de cada lote.

\section{Análise de variabilidade pré-pilha}

O material pré-pilha é todo aquele analisado na correia transportadora que alimenta as pilhas de homogeneização. O material proveniente das minas é combinado e transportado por uma Correia de Longa Distância e, quando se faz necessário, o transporte é feito por rodovia exclusiva da empresa, através de caminhões. Apenas o material transportado pela correia é utilizado na formação das pilhas de homogeneização.

Para se ter uma idéia de comportamento do material combinado da Mina 1 e Mina 2, a distribuição das massa, ao longo dos turnos, é mostrada na Figura 5a. Note que a média de valores das massas é de, aproximadamente, 19.000 toneladas.

Como pode ser visto na Figura 5b, houve uma significativa redução de variabilidade, em comparação a qualquer uma das minas individualmente (Figuras 3 e 4). O desvio-padrão dos teores de sílica dos lotes de minério combinados das duas minas com massa média de 19.000 toneladas, em relação ao teor médio anual da referida massa, é de 1,45\%. A variabilidade do sistema foi reduzida em, aproximadamente, $45 \%$, blendando-se o minério das duas minas, em vez de alimentá-lo individualmente na usina.

\section{Variabilidade entre as pilhas}

O método adotado para pilhas de homogeneização pela empresa é o do tipo chevron, o qual consiste no empilhamento do material em camadas sucessivas, umas sobre as outras, ao longo de um eixo longitudinal (Figura 6a). A pilha é formada por um "stacker" e o minério retomado por uma recuperadora de duas rodas de caçamba (Figura 6b). O pátio da empresa possui espaço para duas pilhas de homogeneização, com massa de, aproximadamente, 200.000 toneladas cada. 


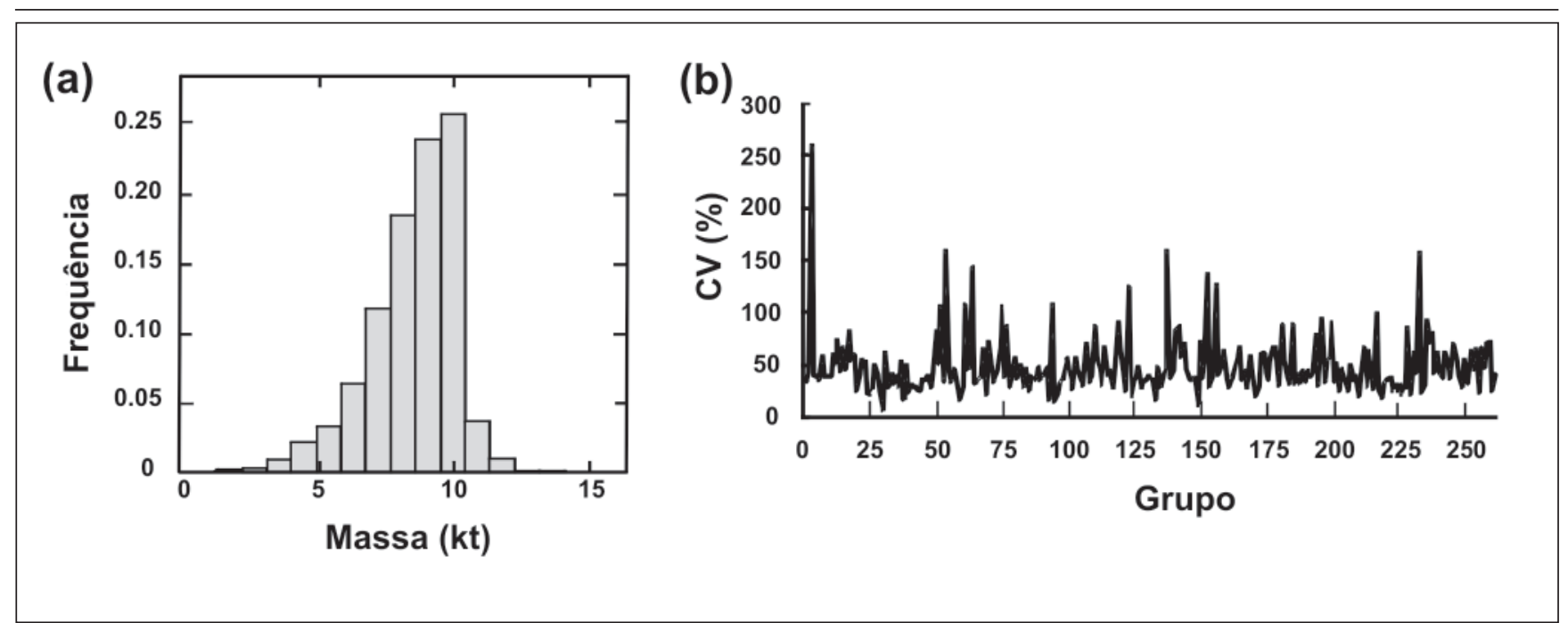

Figura 3 - (a) Histograma das massas e (b) coeficiente de variação de teores da mina 1.

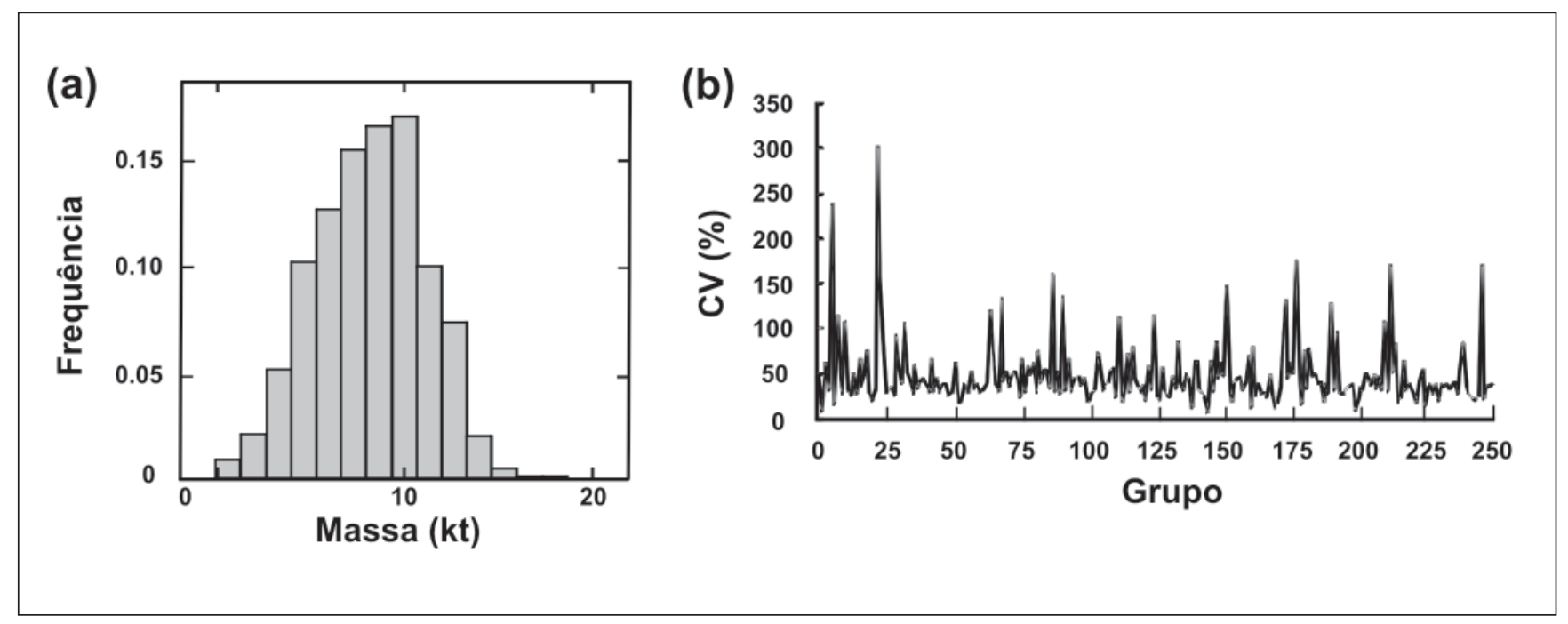

Figura 4 - (a) Histograma das massas e (b) coeficiente de variação de teores da mina 2.

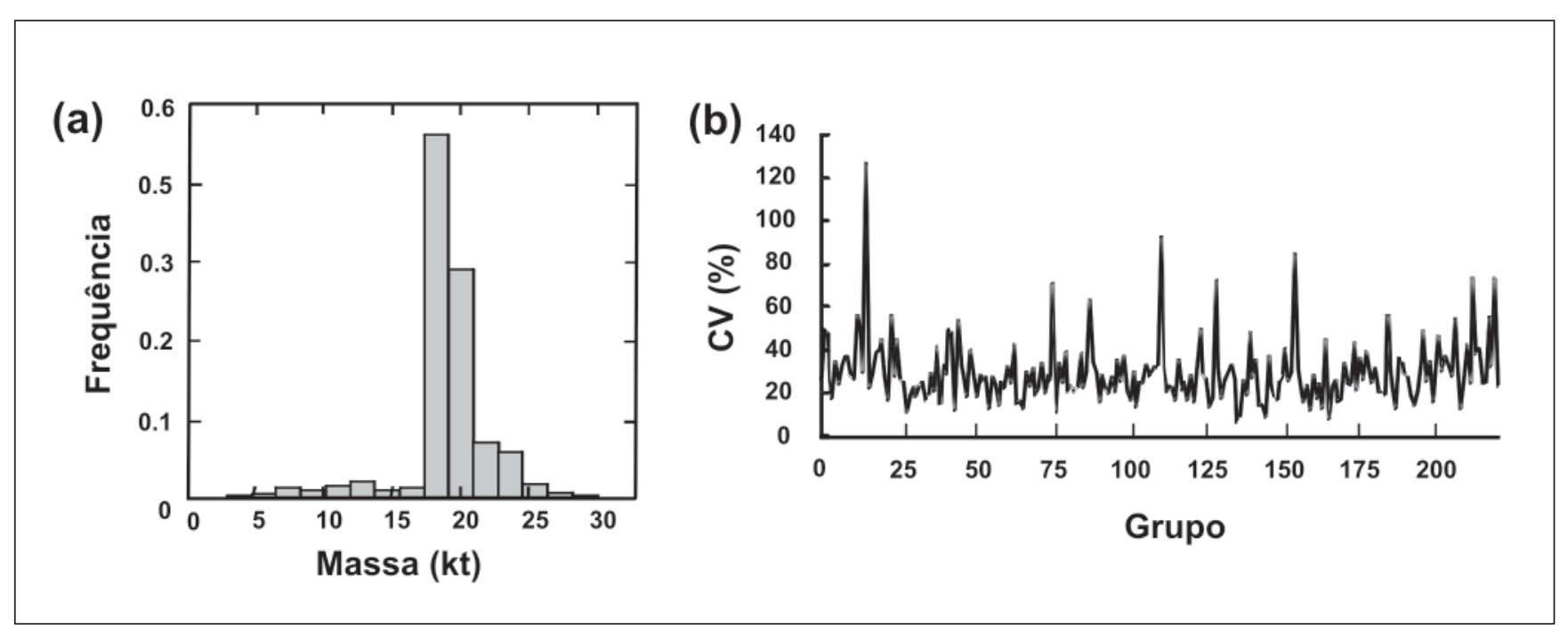

Figura 5 - (a) Histograma das massas e (b) coeficiente de variação de teores pré-pilha. 
Esse é o método mais comumente empregado na indústria, tendo as seguintes vantagens:

i. Permite uma manipulação de forma mais direta, podendo ser realizada a utilização de materiais que atenuem a variabilidade em qualquer momento da formação da pilhas, de forma a deixar o produto dentro das especificações de qualidade requeridas pelo sistema.

ii.O "stacker" pode ser com torre fixa, com sua lança tendo menor comprimento, resultando numa empilhadeira de peso relativamente menor, e com um custo total de instalação mais baixo (Ferreira, 1989).

iii. A automação dos movimentos do equipamento utilizado no empilhamento é mais simples.

No ano em questão, foram montadas 135 pilhas pela empresa com diferentes massas (Figura 7a), gerando 27 grupos de pilhas. Os diferentes tamanhos de pilhas ocorrem devido à alta demanda do mercado pelo minério de ferro, fazendo com que o material tenha um menor tempo de residência no pátio homogeneizador. Esse fato gera pilhas com massa menor que a prevista no projeto do pátio.
Para cada grupo, calcula-se o desvio-padrão dos teores em relação ao teor médio do ano do material que alimenta as pilhas (material pré-pilha). Os resultados são apresentados na forma de gráfico (Figura 7b).

Assim, as pilhas reduzem a variação dos teores que alimentam a usina, se comparados com a variabilidade de teores que se teria, caso a alimentação fosse realizada diretamente do minério oriundo das minas.

Pelo gráfico apresentado, fica claro que, quanto maior a pilha, menor é a variabilidade dos teores em relação a determinado período (neste caso, o ano de 2004). Porém, quanto maior a pilha, maiores serão as dificuldades de operação, os custos envolvidos e o tempo de residência do material em estoque.

\section{Composição da variância do sistema de homogeneização}

A variabilidade do sistema de homogeneização é a soma de todos os desvios-padrão presentes no sistema, podendo ser considerada como a soma de todas as incertezas associadas ao processo. Na Figura 8a, estão apresentadas em um mesmo gráfico, as variabilidades presentes em todo o sistema. Na Figura 8b, fez-se o ajuste de uma função, mostrando que a redução da variabilidade realmente apresenta o comportamento esperado.

Após a quantificação das variabilidades, pode-se montar gráficos como os das Figuras 8a e 8b, as quais associam todas essas variabilidades em função do incremento de massa no sistema, gerando uma equação de ajuste para esse depósito no ano em questão.

O tamanho ideal da pilha será determinado através de considerações da empresa sobre os custos envolvidos, os quais são avaliados em função do ganho na redução da variabilidade que a pilha proporciona. Esse ganho pode ser representado pela Taxa de Redução da Variabilidade (TRV), descrita pela seguinte equação (Bolzan et al., 2006):

$\mathrm{TRV}=\left(1-\frac{\sigma_{\mathrm{m}}}{\sigma_{\mathrm{i}}}\right) \times 100$

onde:

TRV = Taxa de redução da variabilidade. $\sigma_{\mathrm{m}}=$ Desvio-padrão em função do incremento de massa.

$\sigma_{\mathrm{i}}=$ Desvio-padrão inicial (Mina 1).
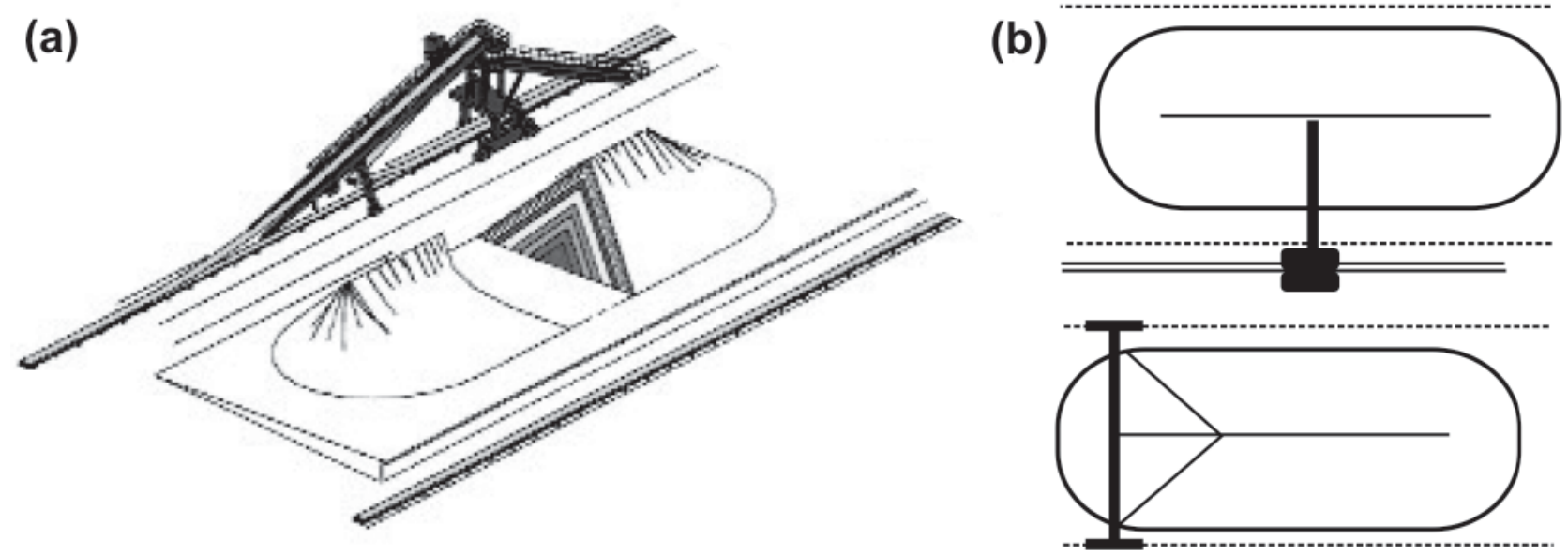

Figura 6 - (a) Pilha tipo chevron e (b) esquema do pátio homogeneizador presente na empresa. 


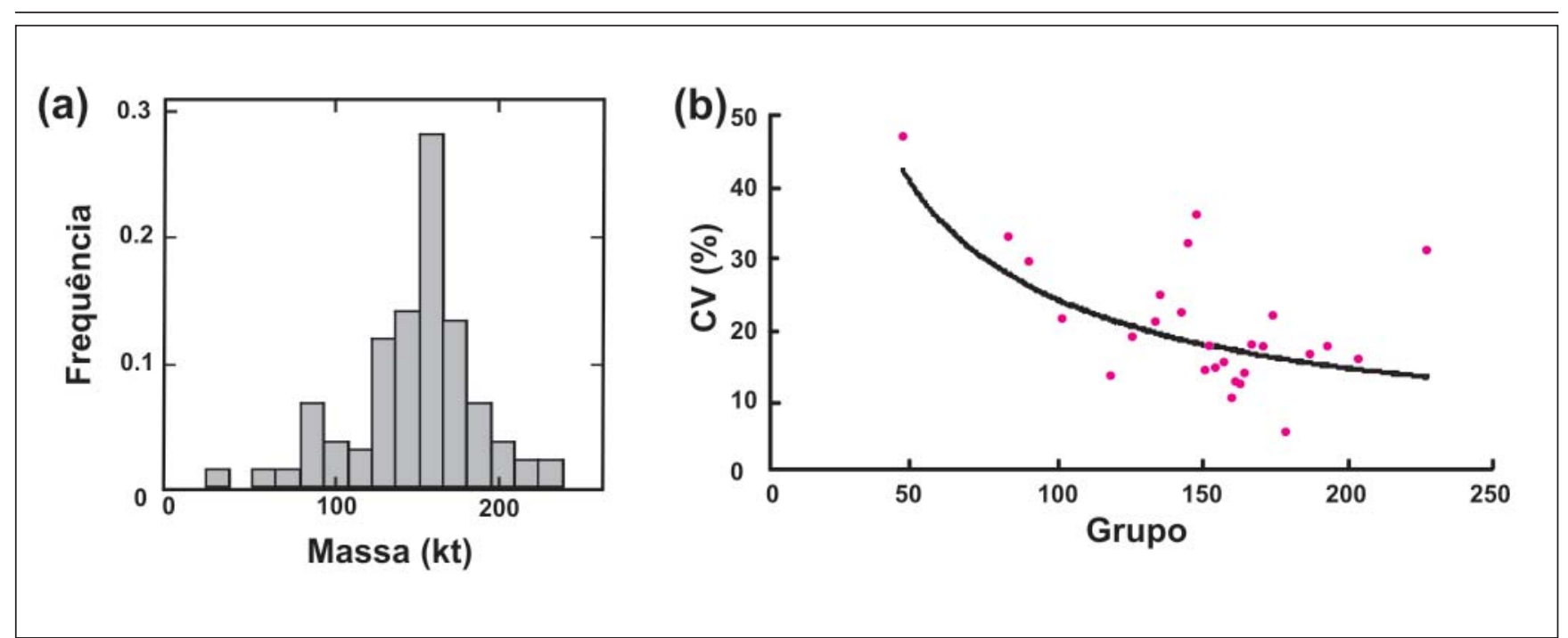

Figura 7 - (a) Histograma das massas e (b) coeficiente de variação de teores nas pilhas de homogeneização em relação ao teor médio anual.

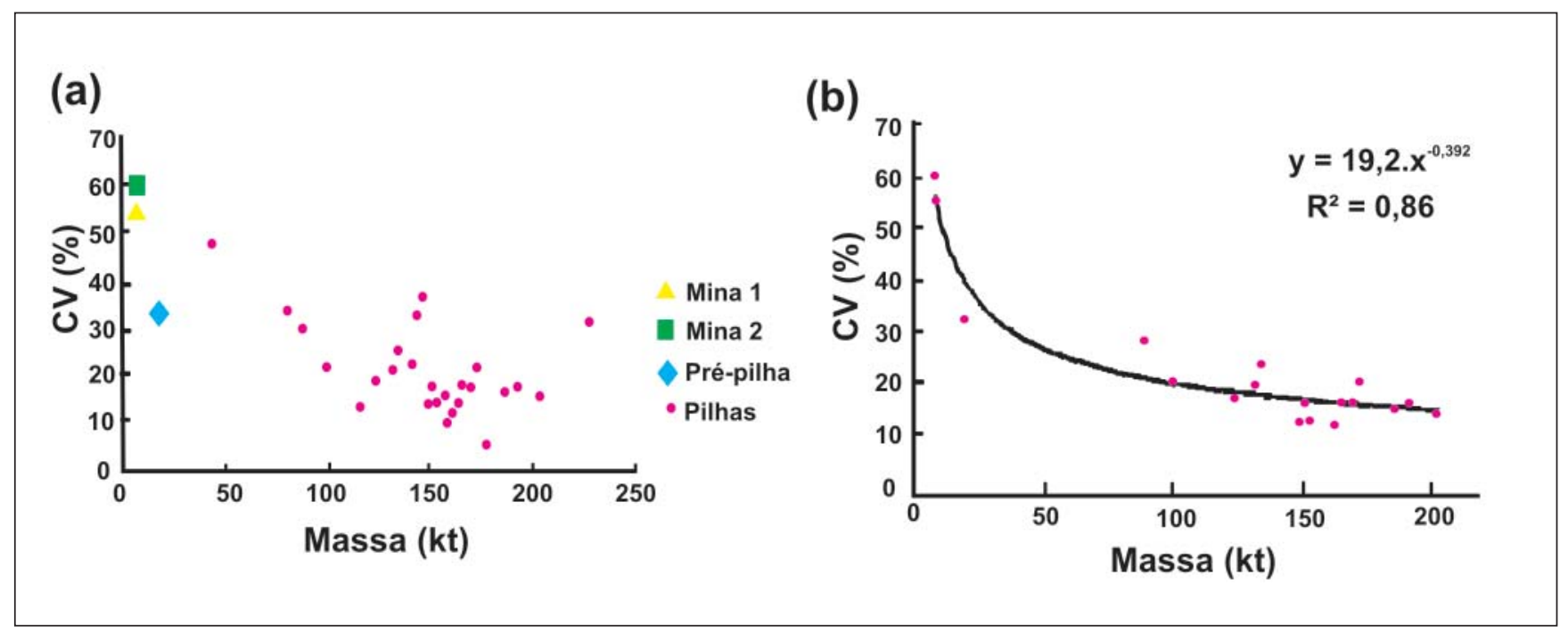

Figura 8 - (a) variáveis do sistema homogeneizador e (b) curva de ajuste representando a redução de variabilidade no sistema para diversas massas consideradas.

Os resultados obtidos, através dessa análise, são mostrados na Figura 9. Pode-se notar uma redução de até $75 \%$ na variabilidade da sílica medida com os teores vindos em cada turno de cada mina, em relação à variabilidade dos teores obtidos após as pilhas de homogeneização.

Pode-se perceber que as reduções de variabilidades significativas ocorrem com o aumento de suporte nas etapas iniciais (blendagem das minas). Após essa etapa inicial, a redução continua a ocorrer, mas apresenta um comportamento assintótico.

\section{Conclusões}

Por meio da metodologia adotada, constatou-se que é possível reduzir, em até $45 \%$, a variabilidade dos teores de sílica, com múltiplas frentes de lavra operando simultaneamente (diferentes minas).

Com o uso de pilhas de homogeneização, constatou-se que é possível reduzir em até $75 \%$, a variabilidade dos teores de sílica medidos turno a turno.

A operação de um sistema de homogeneização traz diferentes ganhos na redução da variabilidade e tais ganhos estão diretamente ligados à forma como o referido sistema é utilizado. 
As etapas iniciais do aumento de suporte apresentam a redução de variabilidade mais significativa do sistema. O comportamento da variabilidade, em função do aumento de suporte, segue a tendência esperada.

\section{Referências}

\section{bibliográficas}

BOLZAN, I.P., COSTA, J.F.C.L., RIBEIRO, D.T., PILGER, G.G., BATISTON, E.L., MARQUES, D.M., KOPPE, J.C. Aperfeiçoamento da estratégia de homogeneização de minérios utilizando simulação geoestatística. Laboratório de pesquisa mineral e planejamento mineiro, UFRGS, 2006. 51p. (Relatório Interno).

FERREIRA, M.F. Otimização do projeto de pátio de homogeneização através do método de simulação condicional. São Paulo: Escola Politécnica da Universidade de São Paulo, 1989. 116p. (Dissertação de Mestrado).

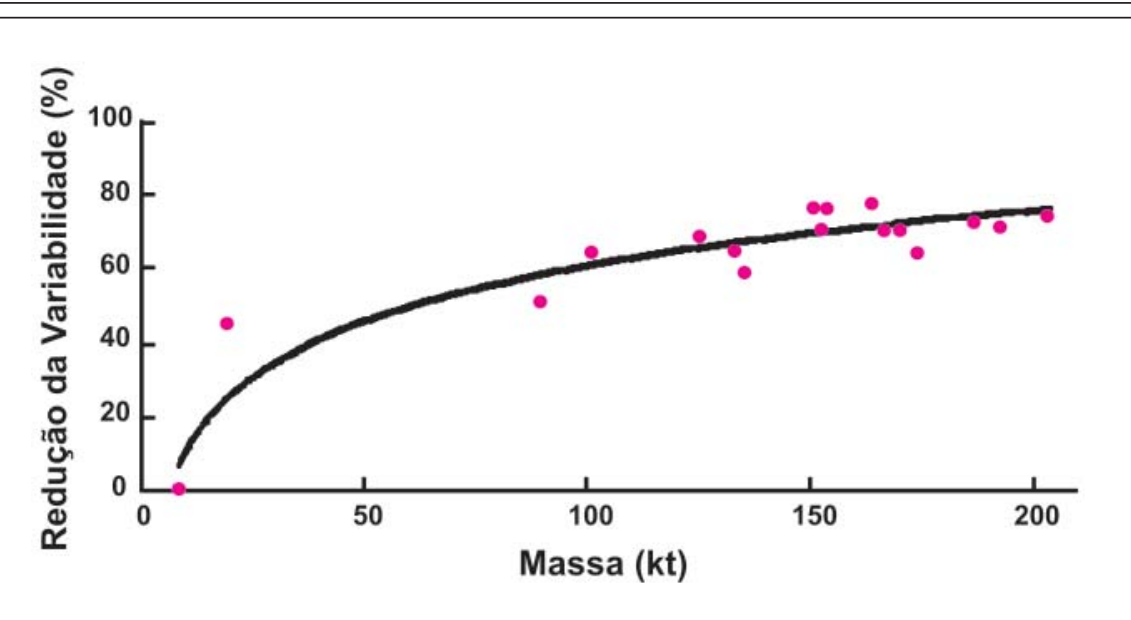

Figura 9 - Redução de variabilidade em função do incremento de massa no sistema.

GY, P.M. Sampling for analytical purposes. Chichester: John Wiley \& Sons, 1998. 153p. PARKER, H. The Volume-variance relationship: a useful tool for mine planning. Engineering and Mining Journal, v. 180, p. 106-123, 1979.

SCHOFIELD, C.G. Homogenization/blending systems design and control for minerals processing. Germany: TransTech Publications, 1980. 236p.

Artigo recebido em 12/11/2008 e aprovado em 22/05/2009.

\title{
Descubra as muitas informações da:
}

\section{Geologia, Mineração, Metalurgia \& Materiais} e Engenharia Civil.

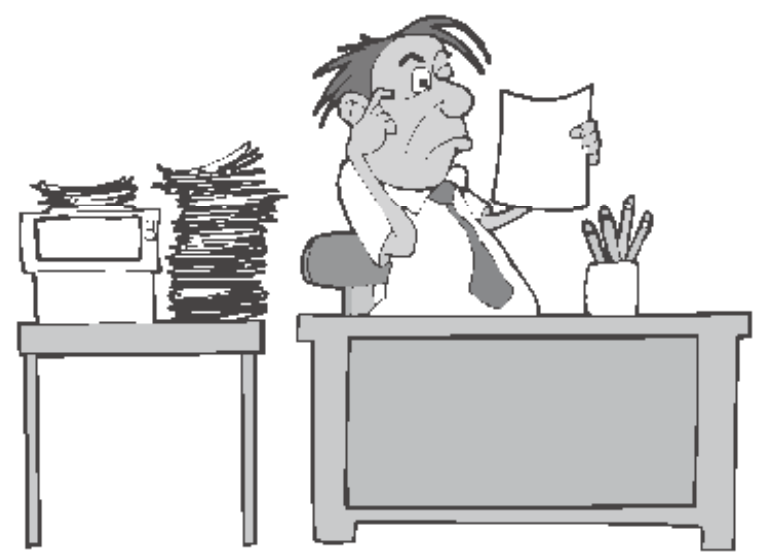

\author{
Assine e \\ publique \\ na Rem
}

Conheça o nosso site: WWW.rem.com.br 